\title{
CREATING COMMUNICATION CONDUITS: A Greater Yellowstone ScIENCE LEARNING CENTER INTERNSHIP
}

\author{
ELIZABETH E. PERRY \\ OREGON STATE UNIVERSITY $\downarrow$ CORVALLIS, OREGON
}

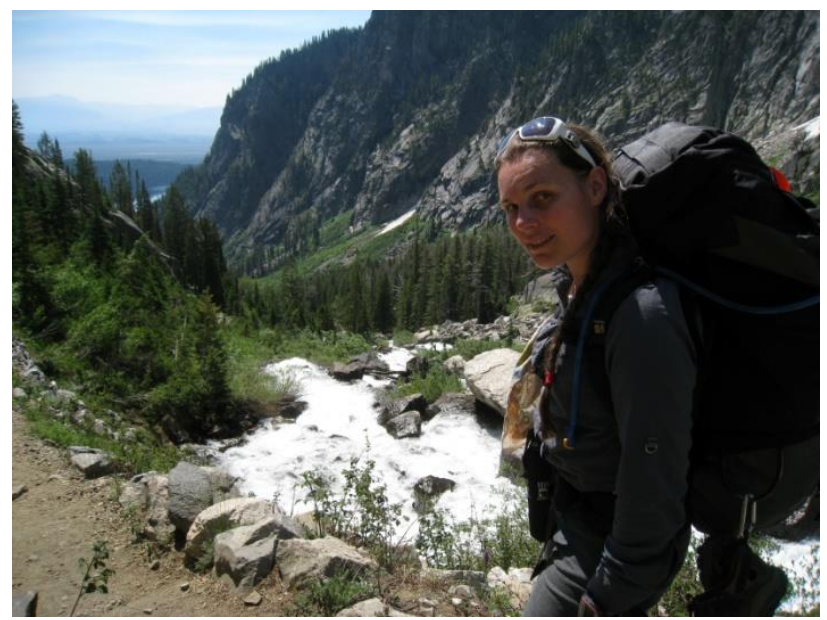

\begin{abstract}
$\uparrow \quad$ ABSTRACT
Communicating scientific endeavors in a manner accessible to researchers, managers, and the public alike is an important, yet often neglected, aspect of conducting studies. For research carried out on America's public lands, including the National Park Service's, this communication is even more important, as we are all owners and stewards of these magnificent ecological and cultural landscapes. This summer, I worked with The Greater Yellowstone Science Learning Center, Grand Teton National Park, and researchers from across the country to augment and enhance the information about current park studies and resource status reports available to the Science Learning Center's website visitors. This addition of pertinent information to the website is of value to all those interested in the socio-ecological landscapes the National Park Service is tasked to conserve, scientific studies occurring in Grand Teton National Park, and potential implications of these studies and findings
\end{abstract}

beyond park boundaries. The additions not only reach those who are currently invested in stewardship of our national parks, but also potential stewards with whom we have the unique opportunity to communicate with digitally, vastly expanding science communication and involvement opportunities.

\section{$\downarrow$ INTERNSHIP SUMMARY}

Communicating scientific studies and the status of park resources falls directly in line with the National Park Service's mission to conserve protected surroundings and provide for future generations' enjoyment. Without conducting inquiries as to the nature of the park's resources and visitors' experience, and relaying this information to a wide audience of stakeholders (i.e., the American public and park enthusiasts world-wide), we leave the mission unfulfilled. This summer, to better communicate the research in Grand Teton National Park (GRTE) and to support this mission, I spent 10 weeks assisting in 
creating a fuller representation of the park's projects and resources on the Greater Yellowstone Science Learning Center (GYSLC) website.

Working with Sue Consolo-Murphy (Chief of Science and Resource Management) and Holly McKinney (primary content creator for GRTE on the website), I formed initial priorities for my summer's internship. Resource briefs are important components of the website and assist visitors in obtaining a detailed snapshot of a park resource's current status. I focused a portion of my internship on learning about mountain goats in the area and correspondingly conducting a major re-write of the current resource brief on this topic, with input from knowledgeable park staff and sources.

As Ms. McKinney focuses on resource briefs, and I have prior experience creating them, we determined the best use of my internship would be to focus on a complementary and equally important aspect of the site: the park projects, including the Boyd Evison Fellowship. This would help expand my skill set while providing GRTE with a relevant product. Therefore, I strived to update all the Fellowship recipients/projects pages and enter all of GRTE's 2012 permitted research projects onto the site. I successfully accomplished both, updating and expanding information on all of the Fellows' pages, increasing the number of projects on the site by $17 \%$, and updating many ongoing projects, resulting in additions or edits to $25 \%$ of the projects linked to the GYSLC site (Table 1).

One of the main reasons I focused on projects (beyond it being a need and information gap for GRTE), is that I actively sought out communicating directly with researchers about their projects and soliciting further information for posting. I feel this was a great accomplishment of my time here, as I was able to contact many researchers and work with them to present their projects in a way that encompassed the park's commitment to resource protection and science, as well as the need for adequate and appropriate communication of these aspects with the public. Indeed, I contributed additional information or new profiles for 45 researchers, constituting $18 \%$ of the researchers currently listed for the entire site (Table 1). Through these communications, I gained access to images, reports, and multimedia presentations that invite site visitors to explore topics more in-depth. These communications led to edits of $3 \%$ of the overarching topic pages listed, a $6 \%$ increase in the number of products linked to the site (Table 1), and an undoubtedly larger percentage of products linked specifically to GRTE. Throughout this summer, I kept careful track of my progress through file structure and digital spreadsheets, as sound data management is vital for park staff to continue efficiently with projects (such as with a short internship) and preserve the institutional memory of what has been accomplished.

Many times, researchers do a wonderful job of communicating within their community but a lesser job with engaging others in a dialog about scientific endeavors in protected areas. It was my intention this summer to learn more about how to foster and promote this communication among user groups and site visitors, as it is a career skills goal of mine. In working with different researchers and park staff, I feel that I learned a variety of avenues by which to approach scientific communications for both broad and specific audiences. All of these successes helped to raise the profile of GRTE on the website and to the visitors.

Numbers alone cannot capture what this internship personally meant for me. With a strong interest in science communication and increasing park relevancy to visitors, I was eager to explore this in a national park setting. In a park as iconic as GRTE, the opportunity to work with park researchers and staff, to make their scientific inquires more accessible to their fellow researchers, management staff, and the public, was incredible. I developed skills this summer that will be useful not only for application to my M.S. thesis on public knowledge and perceptions of the newly established Oregon marine park system, but also in my career, hopefully in the capacity of a National Park Service science communications specialist or social scientist. As park stewards continuously access the Internet to a greater degree for information on their favorite parks, working with the GYSLC to relay information to this audience allowed me to gain experience in communicating via this influential and dominant medium.

Of course, spending the summer in a location such as GRTE was rewarding beyond the work day. I especially enjoyed living at the AMK Ranch and interacting with researchers there. I took full advantage of the location as well and hiked the majority of the park's main trails this summer, leaving no major area unexplored. Through the internship, these explorations, and conversations with staff and visitors, I came to profoundly appreciate all the park's resources and its place within the National Park Service system and mission. These explorations helped deepen my understanding of resource management complexity and diversity and the importance of effective navigating the ecologicalsocial nexus of protected areas. Combined with my work on the website, this experience at GRTE helped 
to further my desire to build a career fostering an involvement in and attachment to protected areas, which are multifaceted and never consist of solely a natural or cultural fabric. These two interwoven components meld together in sites such GRTE's, sharing narratives rooted in the ecological and social landscape. This landscape is expressed on the GYSLC site and I feel privileged to have had a role in expanding it through this internship.
Table 1. Greater Yellowstone Science Learning Center website content updated and created by Elizabeth E. Perry during summer 2012.

\begin{tabular}{|c|c|c|c|c|}
\hline \multirow[b]{2}{*}{$\begin{array}{c}\text { Entry } \\
\text { Category }\end{array}$} & \multicolumn{4}{|c|}{ Content Category } \\
\hline & Researchers & Projects & Products & Topics \\
\hline $\begin{array}{l}\text { Updated } \\
\text { Entries }\end{array}$ & 12 & 25 & 5 & 5 \\
\hline New Entries & 33 & 33 & 26 & 0 \\
\hline $\begin{array}{c}\text { Total Entries } \\
\text { on Site }\end{array}$ & 248 & 229 & 485 & 168 \\
\hline $\begin{array}{l}\text { Percentage } \\
\text { Added / } \\
\text { Improved } \\
\text { upon }\end{array}$ & $18 \%$ & $25 \%$ & $6 \%$ & $3 \%$ \\
\hline
\end{tabular}

www.greateryellowstonescience.org 